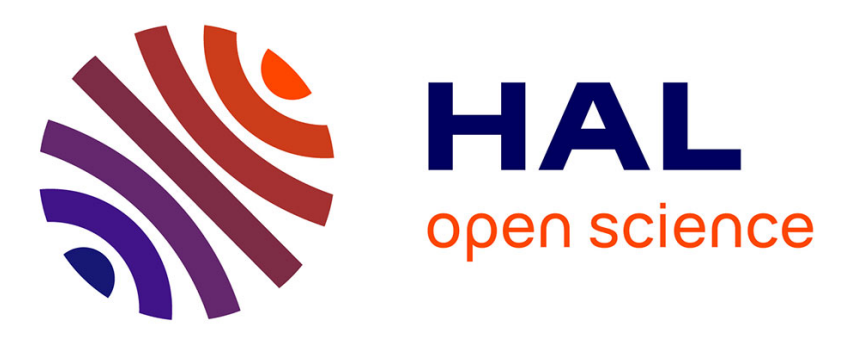

\title{
Shear wave velocity dispersion analysis in placenta using 2-D transient elastography
}

Samuel Callé, Emmanuel G. Simon, Marie-Coline Dumoux, Franck Perrotin, Jean-Pierre Remenieras

\section{- To cite this version:}

Samuel Callé, Emmanuel G. Simon, Marie-Coline Dumoux, Franck Perrotin, Jean-Pierre Remenieras. Shear wave velocity dispersion analysis in placenta using 2-D transient elastography. Journal of Applied Physics, 2018, 123 (23), pp.234902. 10.1063/1.5024309 . hal-02002651

\section{HAL Id: hal-02002651 https://hal.science/hal-02002651}

Submitted on 4 Jun 2019

HAL is a multi-disciplinary open access archive for the deposit and dissemination of scientific research documents, whether they are published or not. The documents may come from teaching and research institutions in France or abroad, or from public or private research centers.
L'archive ouverte pluridisciplinaire HAL, est destinée au dépôt et à la diffusion de documents scientifiques de niveau recherche, publiés ou non, émanant des établissements d'enseignement et de recherche français ou étrangers, des laboratoires publics ou privés. 
Shear wave velocity dispersion analysis in placenta using 2-D transient elastography

Samuel Callé, Emmanuel Simon, Marie-Coline Dumoux, Franck Perrotin, and Jean-Pierre Remenieras

Citation: Journal of Applied Physics 123, 234902 (2018); doi: 10.1063/1.5024309

View online: https://doi.org/10.1063/1.5024309

View Table of Contents: http://aip.scitation.org/toc/jap/123/23

Published by the American Institute of Physics 


\title{
Shear wave velocity dispersion analysis in placenta using 2-D transient elastography
}

\author{
Samuel Callé, ${ }^{1, a)}$ Emmanuel Simon, ${ }^{2,3}$ Marie-Coline Dumoux, ${ }^{4}$ Franck Perrotin, ${ }^{2,3}$ \\ and Jean-Pierre Remenieras ${ }^{2}$ \\ ${ }^{1}$ GREMAN UMR 7347, Université de Tours, CNRS, INSA Centre Val de Loire, 10 rue Thalès de Milet, \\ 37071 Tours Cedex 2, France \\ ${ }^{2}$ UMR 1253, iBrain, Université de Tours, Inserm, Tours, France \\ ${ }^{3}$ Department of Obstetrics, Gynecology and Fetal Medicine, University Hospital Center of Tours, Tours, \\ France \\ ${ }^{4}$ Vermon SA, 180 rue du General Renault, BP 93813, 37038 TOURS Cedex 1, France
}

(Received 31 January 2018; accepted 31 May 2018; published online 19 June 2018)

\begin{abstract}
Preeclampsia and intrauterine growth restriction are related to placental insufficiency and constitute a major public health challenge. Significant changes in placental microarchitecture have already been described in these situations, including, for example, increases or decreases in the number of villi ramifications and the presence of fibrin deposits in terms of villi. These changes affect the entire placenta and might lead to variations in elasticity compared to normal placentas. In this context, we proposed to develop a 2-D transient elastography system, dedicated to the placenta and adapted for in vivo measurements, based on the coupling of a shear wave generated by an external vibration and ultrasound images acquired at an ultrafast rate. To be particularly sensitive to the structure of this organ, a frequency analysis of the complex shear modulus has been realized by applying a fractional rheological model. This model provides a parameter $\mathrm{n}$ which could be sensitive to a shape factor, for example, the variations in the number of villi ramifications in the case of placental insufficiency. An ex vivo feasibility of the method on 20 normal placentas is presented in this work. Published by AIP Publishing. https://doi.org/10.1063/1.5024309
\end{abstract}

\section{INTRODUCTION}

The placenta is a temporary organ, with a continuous and progressive evolution of its structure and function throughout pregnancy. At delivery, the human placenta appears as a round or oval disk measuring $18-20 \mathrm{~cm}$ in diameter and weighing about $500 \mathrm{~g}$. Its functional unit is the cotyledon representing the intervillous space between two placental septa in which bathe chorionic villi. The fetal blood circulates in the chorionic villi, and exchanges between maternal and fetal compartments are carried out through the villi structure (Fig. 1).

Placental insufficiency is related to two major diseases: preeclampsia and intra-uterine growth restriction (IUGR). Preeclampsia is defined as hypertension and proteinuria after 20 weeks of gestation, while IUGR is an arrested or restricted fetal growth between two different examinations at 3-week interval. Preeclampsia occurs in $2 \%-8 \%$ of pregnancies. ${ }^{1}$ In the United States, the prevalence of newborns small for the gestational age $\left(<10\right.$ th percentile) was $8.3 \%$ in 2003 . $^{2}$ These two clinical expressions of placental insufficiency (preeclampsia or IUGR) both have a major impact on perinatal health and are a key challenge in safe childbearing and delivery worldwide.

In clinical practice, the placental function is generally evaluated by investigating the indirect consequences of placental insufficiency: fetal growth, amniotic fluid index, and

\footnotetext{
a) Author to whom correspondence should be addressed: samuel.calle@univtours.fr
}

fetal Doppler indexes. Ultrasound (US) performances for screening of newborns small for the gestational age are limited, with a sensitivity of only $20 \% .^{3}$ Moreover, the practice of ultrasound, even during the third trimester of pregnancy, has no effect on the frequency of maternal or fetal complications. $^{4,5}$ This demonstrates the need for new tools to complement our understanding of placental insufficiency.

The placenta is usually considered primarily from a hemodynamic perspective, but can also be studied as a tissue by investigating its biomechanical properties. US elastography is a relevant tool for such an analysis.

Many studies suggest that consistency of placentas with placental insufficiency may differ from normal functioning placentas. ${ }^{6,7}$ As biomechanical properties of cotyledons cannot be distinguished with conventional US, we hereby propose the use of an adapted US elastography system including the method and apparatus accordingly.

Theoretical and physical considerations indicate that the presence of microscopic obstacles may influence not only the absolute value of viscoelastic tissue parameters, but also their relationship with the frequency. ${ }^{8}$ In the case of placenta exploration, the shear wave velocity variation as a function of frequency is assumed to inform about the placental tissue structure.

Indeed, the frequency analysis could be sensitive to a shape factor of the tissue under consideration. In both diseases, significant changes in the tissue microarchitecture of the placenta, which affect the whole placenta, have been described: for example, increased or decreased villi ramifications $^{9-11}$ and/or fibrin deposits ${ }^{12}$ (Fig. 2). The frequency 


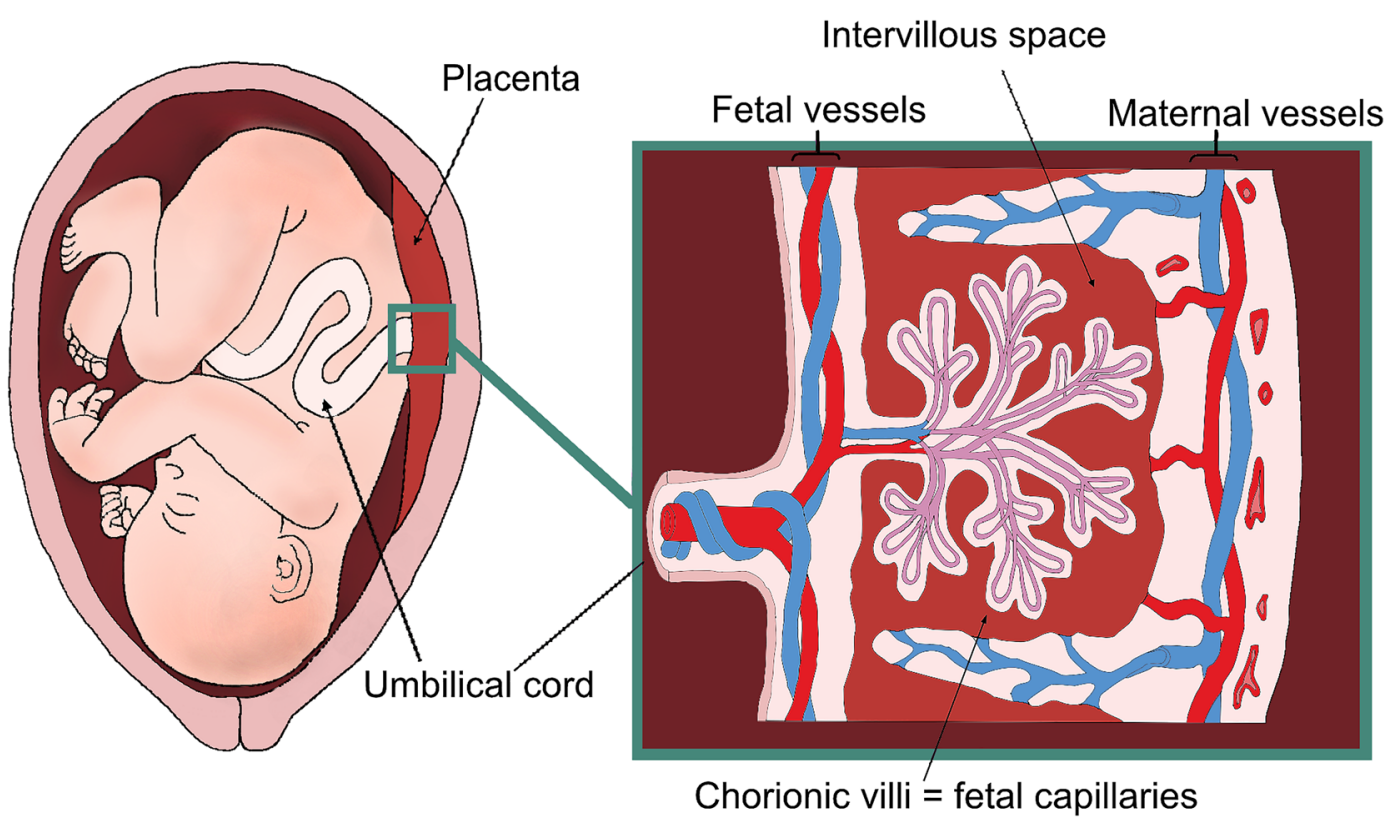

FIG. 1. Schematic view of the placenta showing the branching vascular system of the placenta.

analysis could be very useful for detecting changes in the villous phenotype in the case of IUGR. These changes in angiogenesis constitute a shape factor which could modify the frequency dispersion. Thereby, the analysis of this dispersion could improve the detection of the differences of elasticity in comparison to the conventional parameters (Young's modulus and shear wave velocity at a given frequency).

In this context, we expect to develop a 2D transient elastography method to measure in vivo the dispersion of the shear wave velocity in placenta.

Recently, some studies have evaluated placental elastography, but only one has analyzed the dispersion of shear wave velocity as a function of frequency. ${ }^{13}$ Moreover, the main studies used the radiation force (Shear Wave Elastography). The safety of the radiation force has not yet been formally

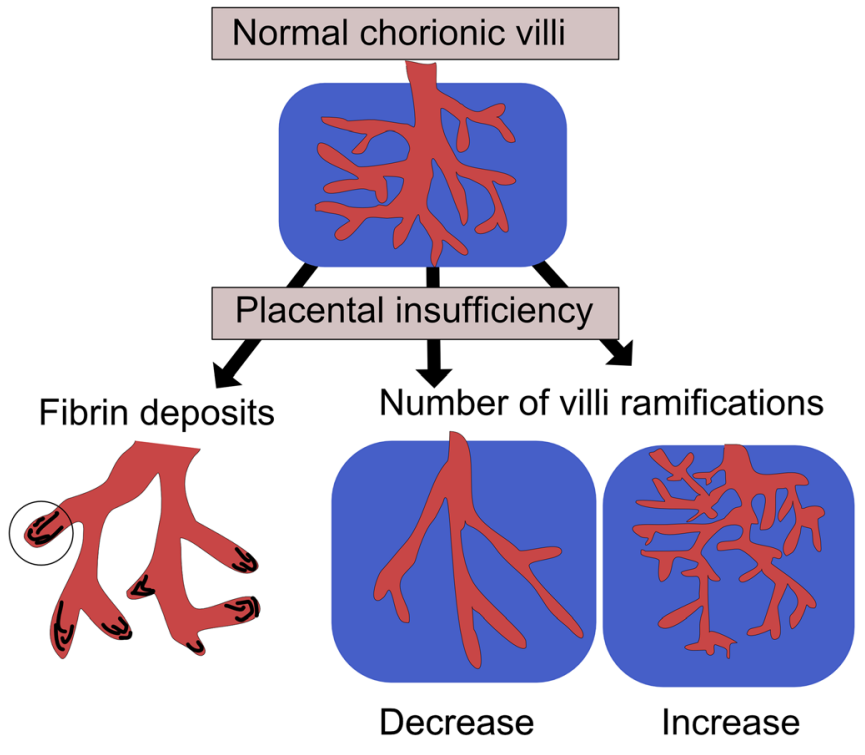

FIG. 2. Normal appearance of the villous tree (above) and changes in placental insufficiency (below): fibrin deposits, decrease or increase in the number of villi ramifications. established for use in pregnant women. ${ }^{14}$ For this reason, we developed a technique of transient elastography which uses a low mechanical vibration rather than intense ultrasonic fields. Recently, Sugitani et al. ${ }^{6}$ applied the ARFI method to ex vivo placentas. In the case of IUGR or hypertensive disorders, they observed a higher placental elasticity compared to normal placentas, but their ultrasonic method did not provide information about the placental tissue structure. Kilic et al. ${ }^{7}$ studied placental elasticity by applying SWE to 50 pregnant women (second or third trimester): 23 preeclampsia and 27 normal pregnancies. In the case of preeclampsia, the median value of Young's modulus was $21 \mathrm{kPa}$ and it was $4 \mathrm{kPa}$ in normal pregnancies. More recently, Abeysekera et al. published a multifrequency analysis of shear wave velocity in placenta using the method called SWAVE. ${ }^{13}$ The latter method is different from ours and consists of continuously transmitting a long wave train. The advantage of SWAVE compared to TE is to generate a higher signal and therefore a better signal-to-noise ratio. In addition, this technique allows the authors to explore higher frequencies than ours. But its main disadvantage is the reverberation issue: the waves are reflected in the organ and these reflections may disturb the elasticity estimation. ${ }^{15}$ A very large compression wave and a small shear wave are observed. On this point, the TE methodology may constitute a significant improvement. In addition, each experiment conducted by SWAVE is done at a single frequency. To obtain values at different frequencies, the experiments must be repeated several times. Our TE method is an impulse method. We immediately emit energy in a frequency band $[20-80 \mathrm{~Hz}]$, which saves us having to repeat the experiment several times.

Preliminary results have been obtained using a 2-D Transient Elastography (TE) method based on the propagation of a plane shear wave generated by a plate fixed to a low frequency (LF) electromechanical actuator and measured using an ultrafast US scanner. ${ }^{16,17}$ In the present work, we 
present ex vivo measurements of shear wave dispersion on normal human placentas with a new system dedicated to in vivo application.

\section{2-D TRANSIENT ELASTOGRAPHY SYSTEM}

\section{A. Materials and method}

To adapt the previously developed system to in vivo application, the proposed TE method is based on the propagation of a shear wave generated by 2 vibrating rods placed on either sides of the US probe (128 elements linear probe SP 5-1 centered at $2.8 \mathrm{MHz}-$ Vermon SA, France), as proposed by Sandrin et al. ${ }^{18}$ As presented in Fig. 3, 2 electrodynamical exciters (Visaton, Germany), completely decoupled from the US probe, induce the LF vibration of the 2 rods. For the purpose of measuring shear wave velocity in placenta, beamformed demodulated IQ data are acquired with an ultrafast US scanner (Aixplorer, SuperSonic Imagine, France): acquisition at $2.8 \mathrm{MHz}$ during $128 \mathrm{~ms}$ with a Pulse Repetition Frequency (PRF) of $4 \mathrm{kHz}$.

\section{B. Characterization of the system: Green's function modelisation}

In an elastic, homogeneous, and isotropic medium, the displacement in the $x_{i}$ direction for an impulse force acting in the $x_{j}$ direction is given by the elastodynamic Green's function ${ }^{19}$
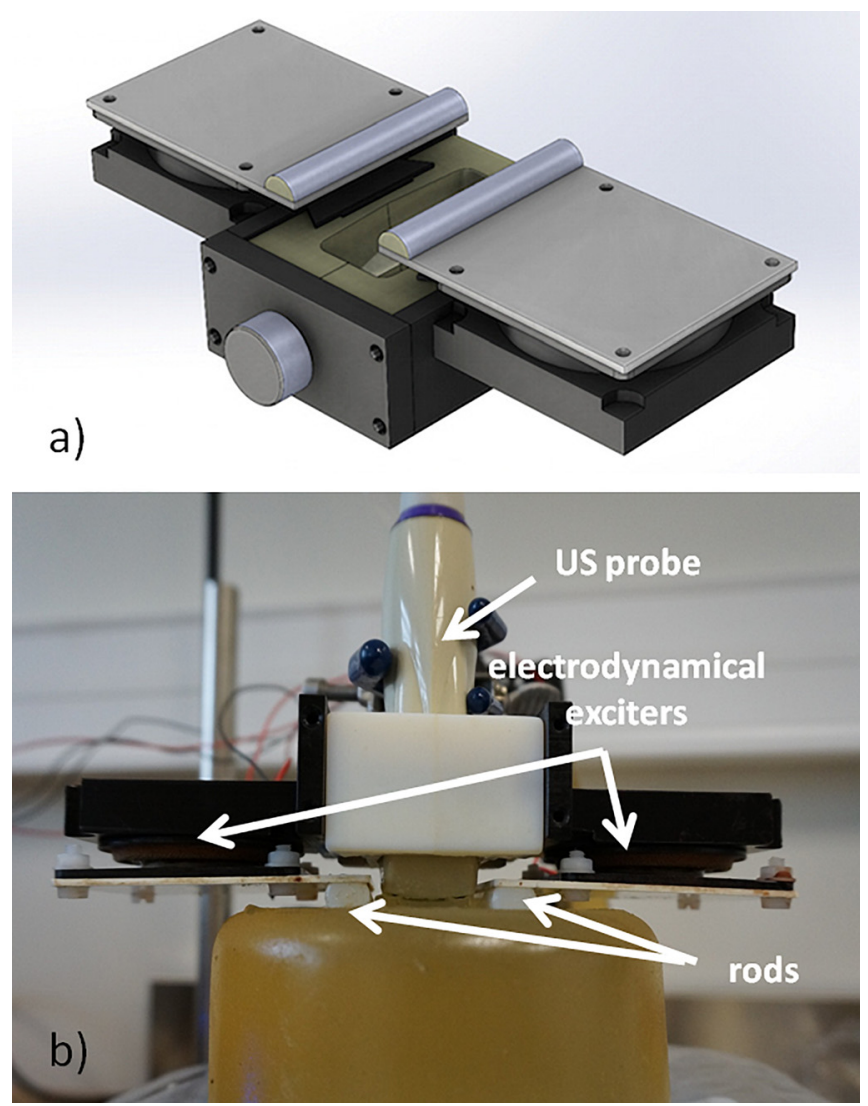

FIG. 3. (a) 3-D modelisation of the device (b) 2-D Transient Elastography system applied to a homogeneous elasticity phantom.

$$
\begin{aligned}
g_{i j}(\vec{x}, t)= & \frac{\left(3 \gamma_{i} \gamma_{j}-\delta_{i j}\right)}{4 \pi \rho} \frac{1}{r^{3}} \int_{\frac{r}{c_{c}}}^{\frac{r}{c_{s}}} \tau \delta(t-\tau) d \tau+\frac{\gamma_{i} \gamma_{j}}{4 \pi \rho} \frac{1}{r} \frac{\delta\left(t-\frac{r}{c_{c}}\right)}{c_{c}^{2}} \\
& +\frac{\left(\delta_{i j}-\gamma_{i} \gamma_{j}\right)}{4 \pi \rho} \frac{1}{r} \frac{\delta\left(t-\frac{r}{c_{s}}\right)}{c_{s}^{2}},
\end{aligned}
$$

where $r=|\vec{x}|=\sqrt{x_{1}^{2}+x_{2}^{2}+x_{3}^{2}}$ is the distance between the point source and the observation point, $\gamma_{i}=x_{i} / r=\partial r / \partial x_{i}$ the direction cosines for the vector $x_{i}, \delta$ is the Dirac function, and $\rho$ is the material density. $c_{c}$ and $c_{s}$ are the compression and shear wave celerities, respectively. This Green's function describes a far-field compression term (second term, longitudinal polarization), a far-field shear term (third term, transverse polarization), and a coupling near-field term (first term, complex polarization). From the radiation patterns of these three terms, ${ }^{20}$ in the case of an unidirectional force along $\mathrm{z}\left(x_{3}\right)$, we can observe (Fig. 4) that a shear wave is generated in the vibration direction, in front of the US probe elements, between the two rods. On the probe axis (z axis), due to the symmetrical positioning of both rods, the two shear contributions in the $\mathrm{x}$ direction vanish and we obtain a purely longitudinal wave propagating in the direction $\mathrm{z}$.

The actual shear wave velocity that originates from the rods is calculated from the propagation distance $\Delta \mathrm{l}$ between two ultrafast acquisitions separated from $\mathrm{T}_{\mathrm{PRF}}$

$$
c_{s}=\frac{\Delta l}{T_{P R F}} .
$$

a)

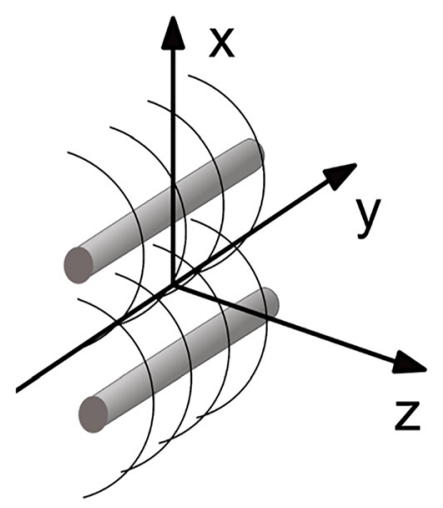

b)

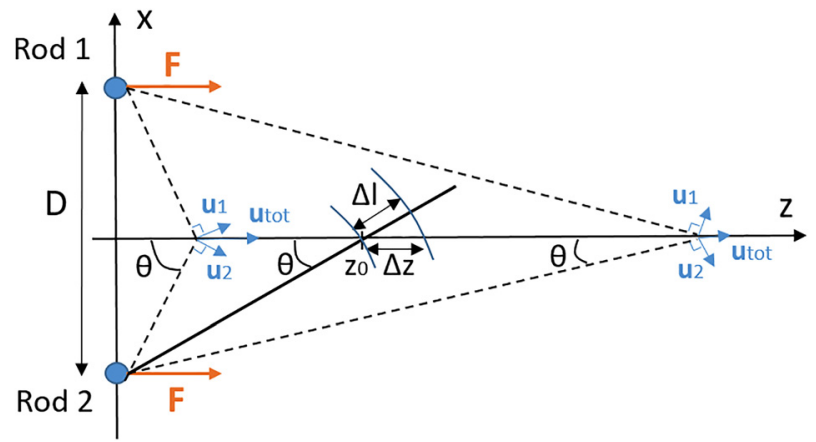

FIG. 4. Construction of the shear wave induced by the 2 vibrating rods along the US probe axis at different distances $\mathrm{z}_{0} . \mathrm{u}_{1}$ and $\mathrm{u}_{2}$ correspond to the displacement contributions of the far-field shear term of the rods 1 and 2 , respectively. $u_{\text {tot }}$ is the total shear displacement induced by the 2 rods. 
But the shear wave velocity calculated by the system along the $\mathrm{z}$ axis is

$$
c_{s, \text { measured }}=\frac{\Delta z}{T_{P R F}} .
$$

Since $\cos (\theta)=\Delta l / \Delta z$, the relative error between the actual and measured shear wave velocities can be expressed as

$$
\frac{c_{s, \text { measured }}-c_{s}}{c_{s}}=\frac{1}{\cos (\theta)}-1=\sqrt{1+\frac{D^{2}}{4 z_{0}^{2}}}-1
$$

where D is the spacing between the rods.

At a distance $\mathrm{z}$ close to the rods $\left(z_{0} \rightarrow 0\right)$, as presented in Fig. 4(b), the contributions of the two rods are highly constructive. However, the wavefront is almost parallel to the $\mathrm{z}$ axis, and the measured velocity is therefore greatly overestimated. At the opposite, when $z_{0} \gg D / 2$, the contributions are not constructive, but the relative error tends to 0 and the measured velocity corresponds to the actual velocity.

To precisely study the radiation pattern of our system from Eq. (1), contributions of the different source points constituting the 2 rods are added. Figure 5 represents the Green's function $g_{33}$ (on the $\mathrm{z}$ axis, $\mathrm{z}_{0}=\lambda_{\mathrm{Cs}}=4 \mathrm{~cm}$ ) in the case of 2 rods ( $5.8 \mathrm{~cm}$ length) separated by $2 \mathrm{~cm}$ (a) and $4 \mathrm{~cm}$ (b) (configuration shown in Fig. 4). The compression velocity is $1500 \mathrm{~m} / \mathrm{s}$ and the shear velocity is $2 \mathrm{~m} / \mathrm{s}$. The amplitude is normalized with respect to the maximum amplitude of the far-field shear term. The far-field compression contributions of both line sources (Dirac functions occurring at very short times) are not visible in the figure because they are negligible (amplitude around $10^{-4}$ ). Each near-field term has a triangular shape. The sum of all near-field contributions has a triangular shape until the arrival time of the source point closest to the observation point (constructive summation), then a decrease to 0 (fewer contributions and from source points farther away from the observation point). The end of the near-field displacement corresponds to the duration of propagation at the shear velocity between the farthest point source and the observation point. The far-field shear contributions are Dirac functions occurring at the times of flight between the source points and the observation point at the shear velocity. We can observe that in each case the main contribution to the shear displacement is due to the far-field shear term.

Radiation patterns of the system along $\mathrm{x}$ and $\mathrm{z}$ axes measured in a homogeneous phantom are presented in Fig. 6. To measure the component $x$ [Figs. 6(c) and 6(d)], the US probe is no longer positioned between the vibrating rods but at 90 degrees, on the $\mathrm{z}$ axis (the vibrating rods are always placed on either side of the $y$ axis). Results are in agreement with the directivities of the different Green's function terms ${ }^{21} g_{13}$ and $g_{33}$, respectively. In the probe plane (YZ plane), as predicted by Fig. 4, displacements $g_{33}$ are constructive and give birth to the quasi plane wave. As expected, displacements $g_{13}$ in the XZ plane are in phase opposition with respect to the central axis.

In the case of a pulse sinusoidal excitation at $50 \mathrm{~Hz}(1$ period), the resulting displacements for a spacing between the rods of 2 and $4 \mathrm{~cm}$ (corresponding to the device) are plotted in Fig. $7\left(c_{c}=1500 \mathrm{~m} / \mathrm{s}\right.$ and $\left.c_{s}=2 \mathrm{~m} / \mathrm{s}\right)$.

As shown in Fig. 4, when $\mathrm{z}$ is small, the wavefronts which come from the rods are parallel to the source lines (rods). Thus, the propagation velocity of the shear wave measured on the $\mathrm{z}$ axis will be very large (overestimation). This overestimation is also due to the near-field term of Equation (1). As stated in Ref. 22, this term dominates within the near-field and its phase velocity is greater than the shear wave velocity. In addition, for small $\mathrm{z}$, the contribution of surface waves is not negligible. ${ }^{23}$

This is seen more particularly in Fig. 7(b) where, due to all these reasons, the shear wave velocity is overestimated in the near-field of propagation. In this case (corresponding to the previously described experimental set-up), the shear wavefront can be considered as plane after about few $\mathrm{cm}$ propagation. This value depends on the distance $\mathrm{D}$ between the two vibrating rods [Eq. (4)].

\section{Shear wave velocity measurement}

Algorithms developed in this work are based on 2D autocorrelation techniques to estimate the velocity displacement of tissue. The IQ signal can be written as

$$
I Q(m, n)=I(m, n)+j Q(m, n)=A(m, n) e^{j \phi(m, n)},
$$
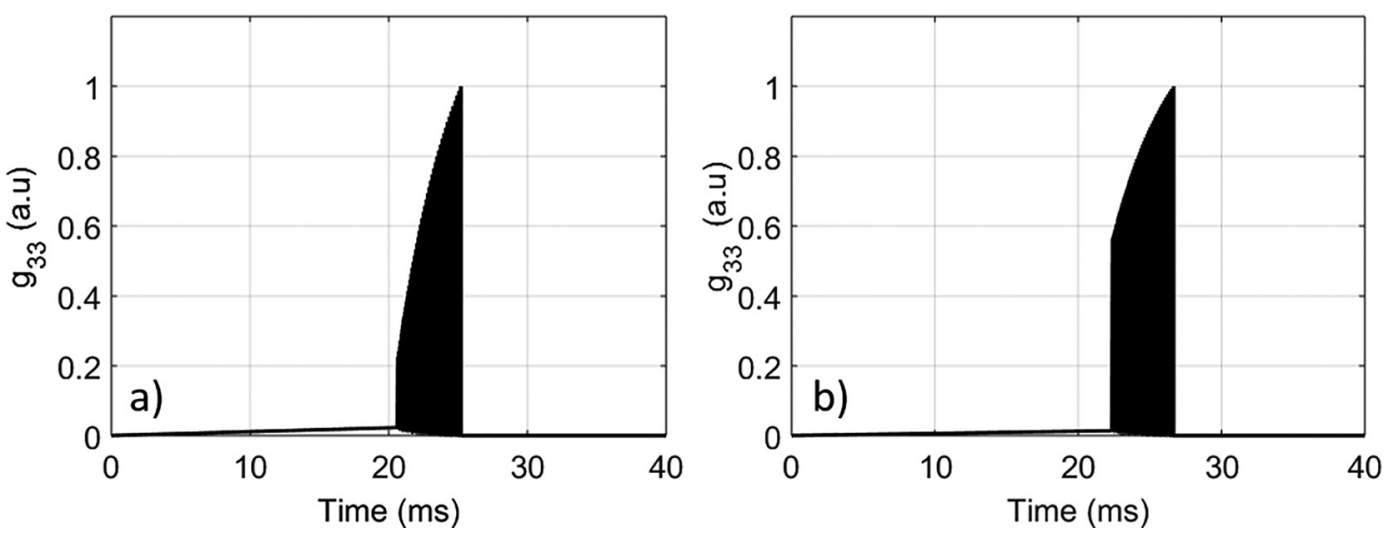

FIG. 5. Representation of the Green's function $g_{33}$ at $\mathrm{z}_{0}=4 \mathrm{~cm}$ generated by 2 line sources spaced: (a) $2 \mathrm{~cm}$ and (b) $4 \mathrm{~cm}$ (experimental set-up). 

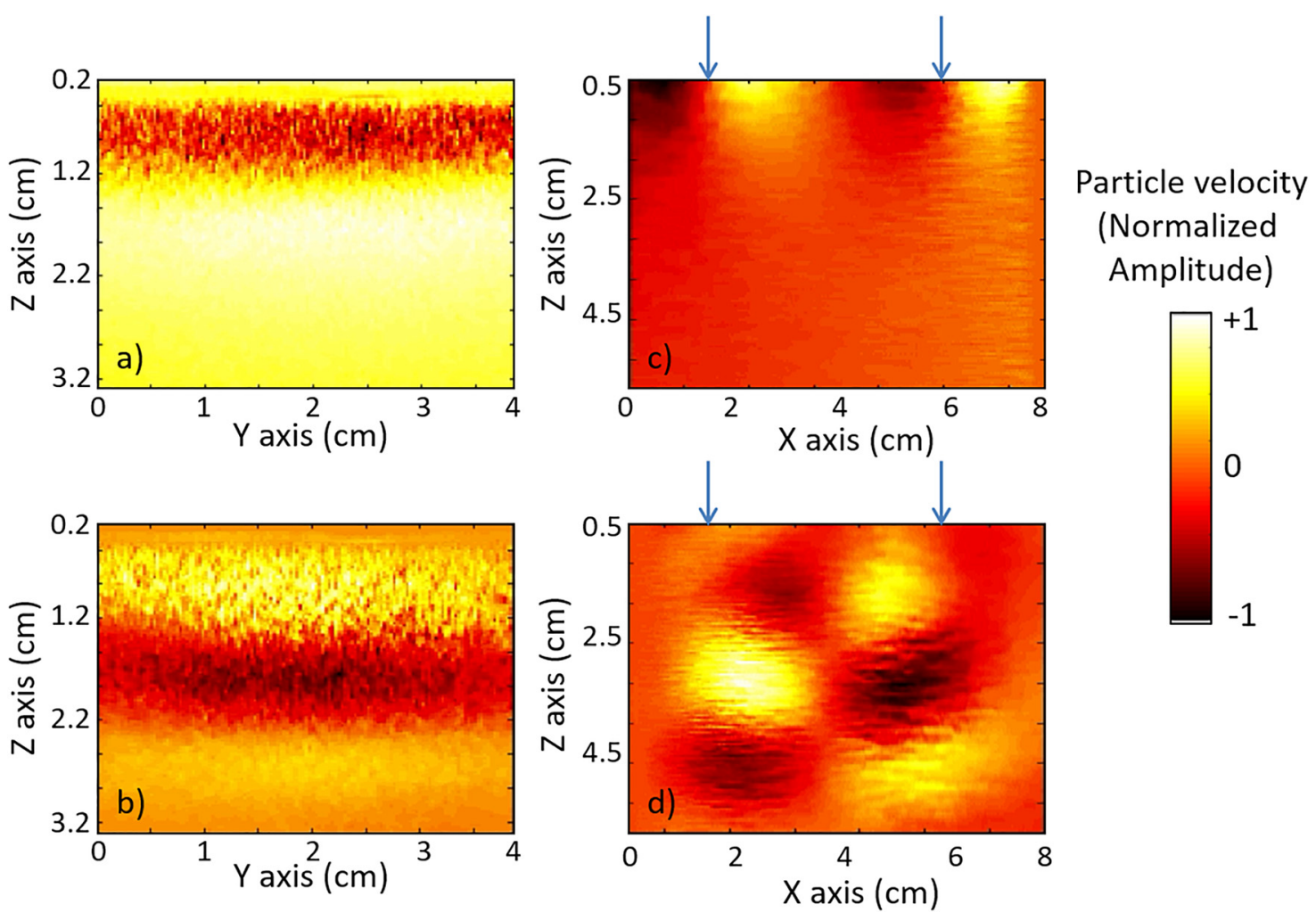

FIG. 6. Measurement of the components $z[x=0$; (a) $t=t 0$ and (b) $t>t 0]$ and $x[y=0$; (c) $t=t 0$ and (d) $t>t 0]$ of the particle velocity (normalized amplitude). The arrows represent the positions of the 2 rods.

where $\mathrm{A}$ is the signal amplitude and $\Phi(\mathrm{m}, \mathrm{n})$ is the phase of the signal returned from the mth depth and the nth pulse. The velocity estimator is defined in (5). It is an extension of the autocorrelation estimator developed by Hoeks et al. ${ }^{24}$ This estimates the mean velocity using multiple, spatially contiguous IQ sample volumes in time. This approach increases the accuracy of the velocity estimated at the expense of decreasing spatial resolution. The mathematical expression is

$$
\begin{aligned}
V(m, n)= & \frac{\lambda}{4 \pi T} \operatorname{Arg}\left\{\sum_{a=0}^{\text {Lapz }} \sum_{b=0}^{\text {Lapt }} I Q(m-a, n-b) \cdot I Q\right. \\
& *(m-a, n-b-1)\},
\end{aligned}
$$

where $\lambda$ is the wave length and $\mathrm{T}$ is the time interval between two acquisitions. Lapz is the number of samples defining the volume of interest and Lapt is the number of temporal samples in the autocorrelation over which the mean velocity $\mathrm{Vz}(\mathrm{z}, \mathrm{t})$ is estimated. Figure 8 represents the compression and shear waves induced by the $2 \mathrm{D}$ TE system in a $3.5 \mathrm{kPa}$ elasticity phantom.

The compression wave propagates almost instantaneously with respect to the shear wave. It has a longer wavelength and its amplitude varies according to $\mathrm{z}$ mainly because of diffraction effects. A spatial derivation with respect to $\mathrm{z}$ applied to the velocity data makes it possible to strongly reduce the amplitude of this compression wave without affecting the shear wave. Moreover, there are also reflected waves (shear and compression) that must be removed. For that, a segmentation is carried out by manually selecting on the elastogram two straight lines: the first on the left of the shear wave to eliminate the remaining compression wave and the second on the right to eliminate the reflected waves.

To study the shear wave velocity dispersion, next steps are performed in the Fourier domain: $\mathrm{Vz}(\mathrm{z}, \omega)$. Based on a plane wave approximation of the longitudinal component of the shear wave, this component can then arise as a combination of cosine and sine whose spatial period is directly related to shear wave velocity

$$
\begin{aligned}
V_{z}\left(z, \omega_{0}\right)= & D(z) \cdot A\left[\cos \left(\frac{\omega_{0}}{c_{s}\left(\omega_{0}\right)} z+\Phi\right)\right. \\
& \left.+j \sin \left(\frac{\omega_{0}}{c_{s}\left(\omega_{0}\right)} z+\Phi\right)\right],
\end{aligned}
$$

with $\mathrm{D}(\mathrm{z})$ a term for diffraction and attenuation effects. A least-squares approximation is used to fit the sinusoidal shape of the real and imaginary parts of $\mathrm{Vz}(\mathrm{z}, \omega)$ (Fig. 9). As previously mentioned, the shear wave velocity can then be deduced from the period of the real or imaginary part of $\operatorname{Vz}(\mathrm{z}, \omega)$. Repeated at any frequency of the LF bandwidth, this allows us to study the shear wave velocity dispersion. The measurement bandwidth is limited by the bandwidth of the excitation: typically between 20 and $80 \mathrm{~Hz}$ in placenta ex vivo to have a signal of amplitude high enough to be analyzed.

\section{Validation on calibrated elasticity phantoms}

The 2D transient elastography system has been tested on tissue-mimicking phantoms. Figure 10 shows the shear 

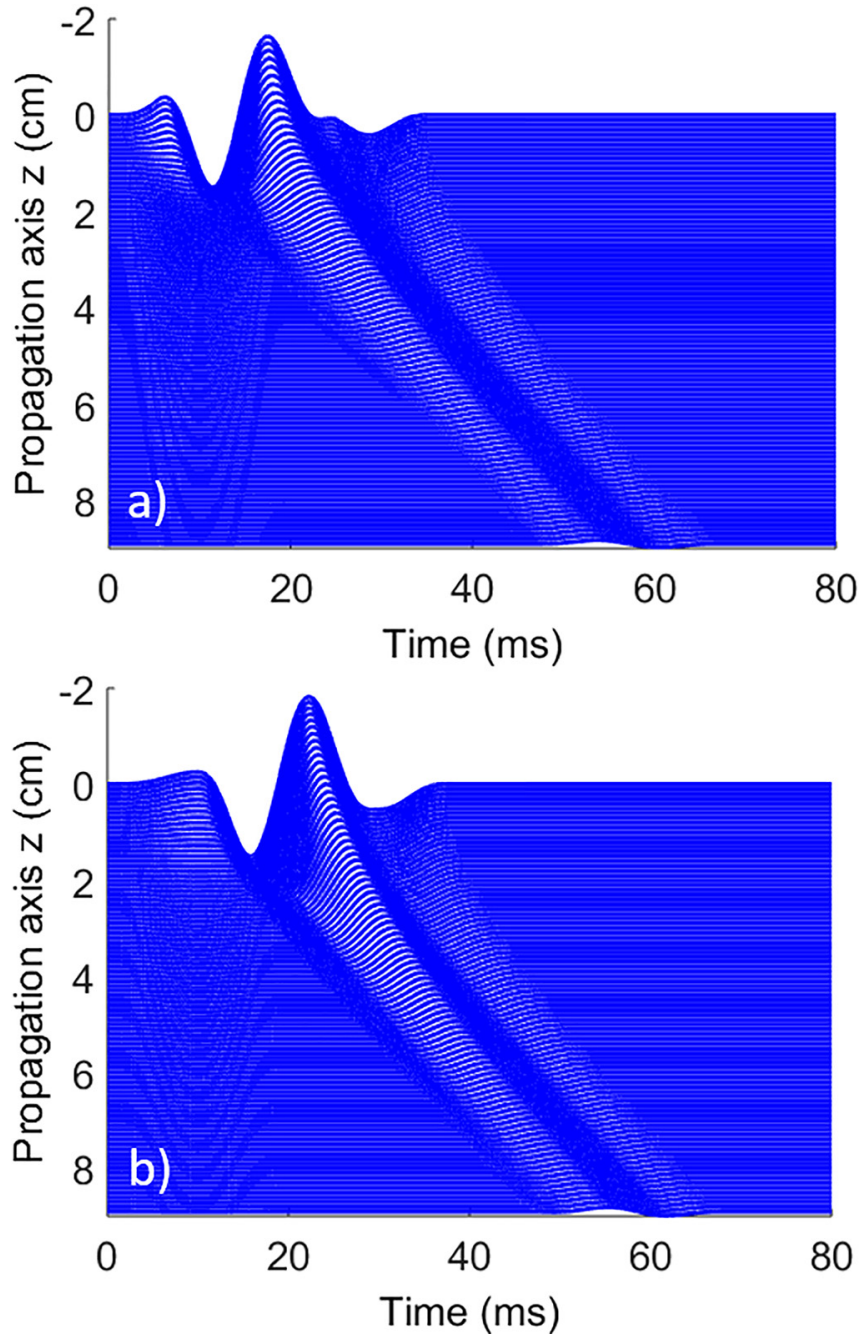

FIG. 7. Simulation of the shear wave propagation induced along the US axis probe by 2 vibrating rods spaced: (a) $2 \mathrm{~cm}$ and (b) $4 \mathrm{~cm}$ (experimental setup).

wave velocity dispersion in two calibrated homogeneous elastic phantoms (phantom $\mathrm{A}: \mathrm{E}=12.1 \mathrm{kPa}$; phantom $\mathrm{B}$ : $\mathrm{E}$ $=3.5 \mathrm{kPa}$ ) made of a mixture of a triblock SEBS copolymer (Kraton Polymers, Univar, France) dissolved in with mineral oil. ${ }^{25}$ As expected, there is almost no dispersion in these media which can be assumed to be purely elastic. Moreover, the shear wave velocity measurements are in

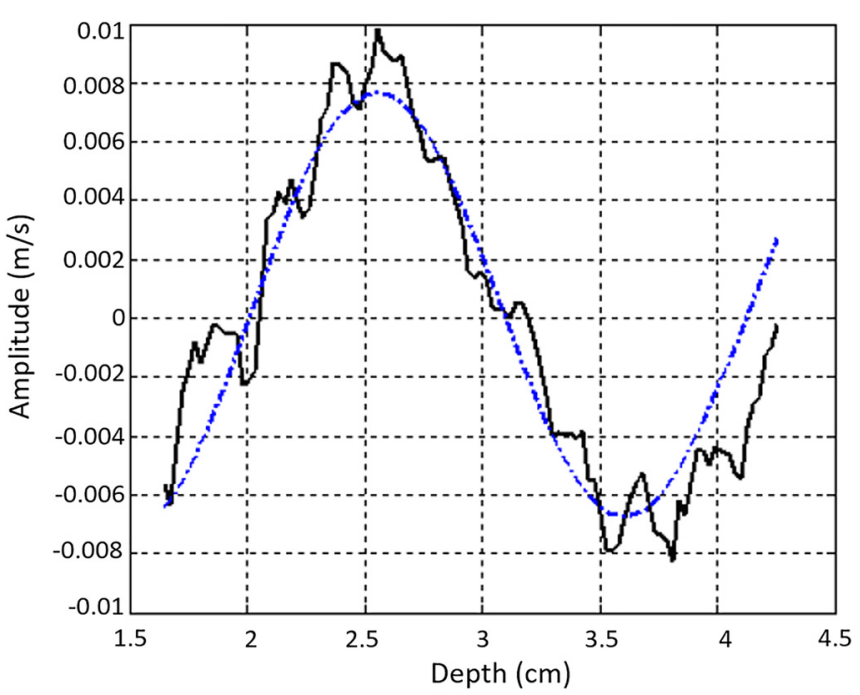

FIG. 9. Interpretation of the real part of $\mathrm{Vz}(\mathrm{z}, \omega)$ using the plane wave approximation.

agreement with phantom data. For example, the shear wave velocity of phantom A $(2 \mathrm{~m} / \mathrm{s})$ is in agreement with its calibrated elasticity $\left(\mathrm{E}=12.1 \mathrm{kPa} ; \rho=1000 \mathrm{~kg} / \mathrm{m}^{3} ; \mathrm{Cs}\right.$ $=\sqrt{ }(\mathrm{E} / 3 \rho)=2 \mathrm{~m} / \mathrm{s})$.

\section{EX VIVO MEASUREMENTS IN PLACENTAS}

\section{A. Measurement protocol}

The method has been applied on 20 normal delivered placentas ( $<12 \mathrm{~h}$ after delivery). The local ethics committee approved this study. Measurements (3 times with repositioning) have been performed in 2 placental regions: a central region (behind the umbilical cord) and a peripheral region (edge of the placenta). At the same time, measurements of the Young's modulus (3 times with repositioning) have been performed using Supersonic Shear Imaging (SSI). Figure 11 represents the experimental set-up.

Figure 12 presents an example of an ex vivo measurement in the placenta. The results are of course more noisy than in the case of a tissue-mimicking phantom (Fig. 8), but it is possible to isolate the shear wave and to calculate the frequency dispersion of the shear wave velocity.

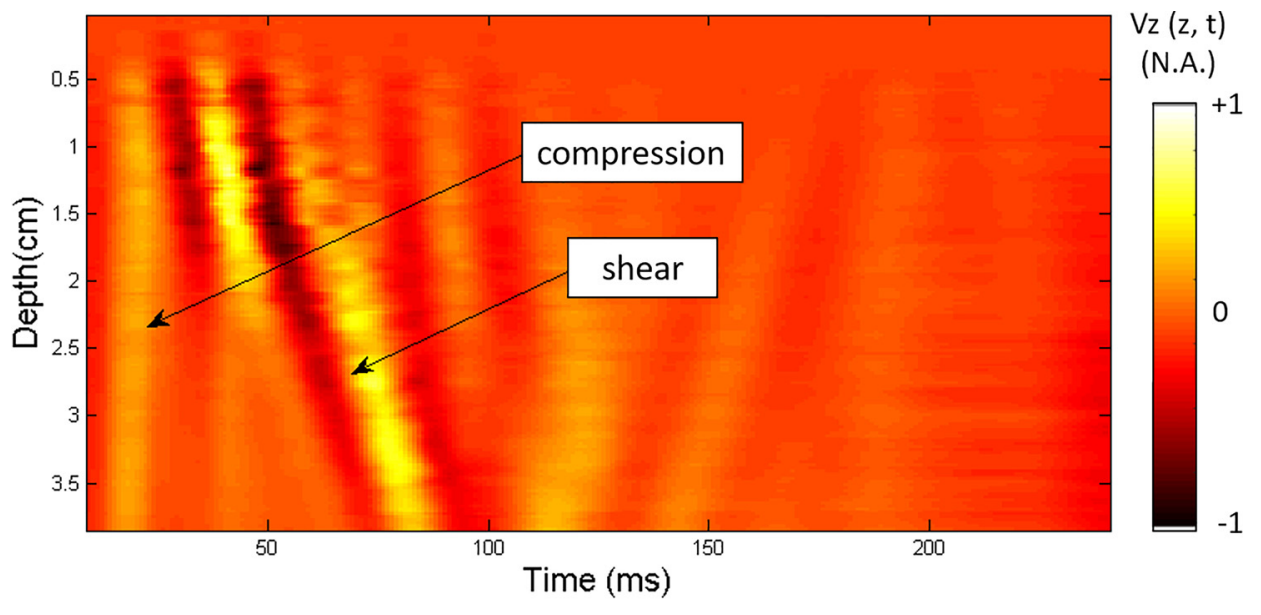

FIG. 8. Particle velocity $\mathrm{Vz}(\mathrm{z}, \mathrm{t})$ measured in a $3.5 \mathrm{kPa}$ elasticity phantom (normalized amplitude). 

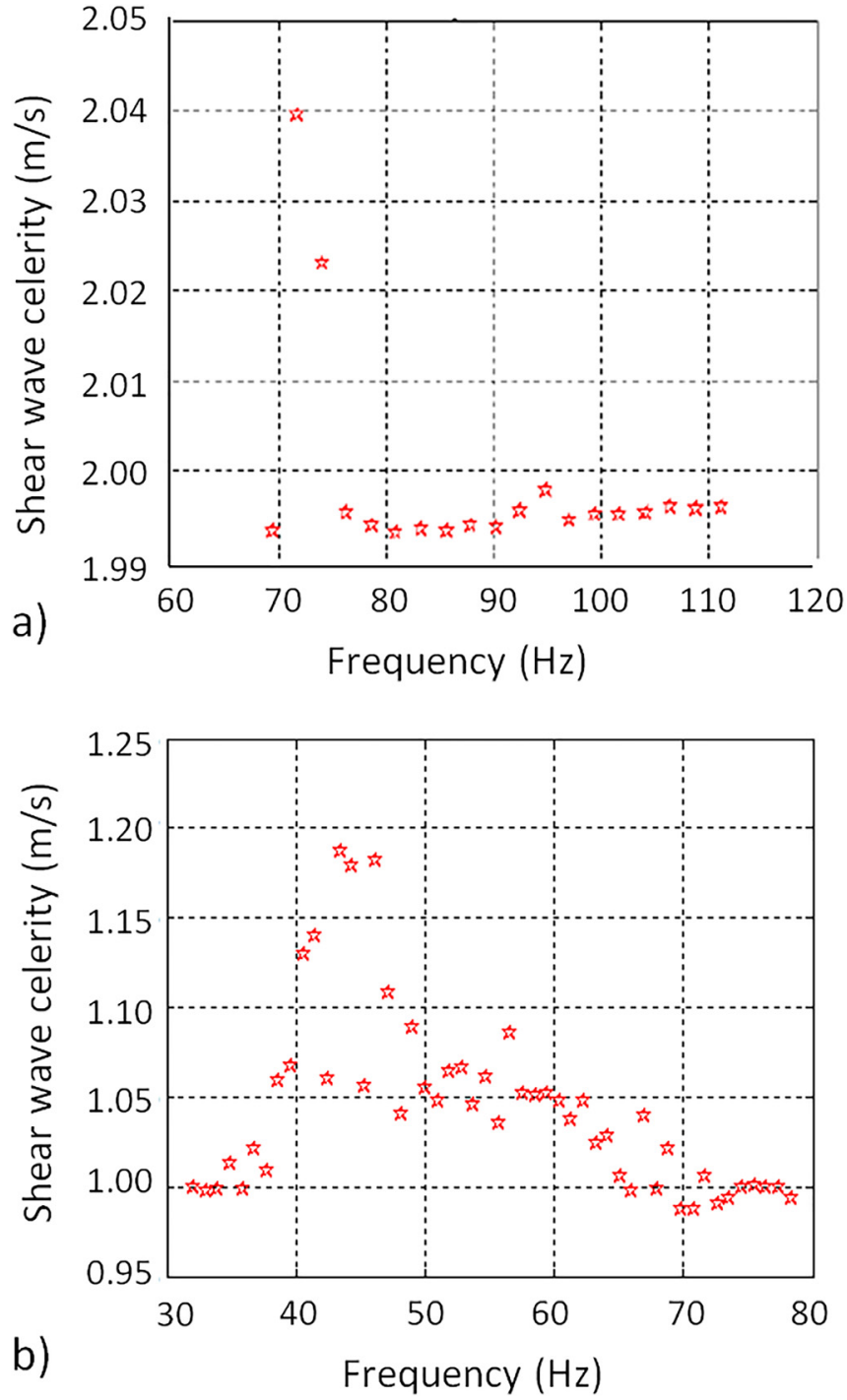

FIG. 10. Shear wave velocity dispersion in calibrated elasticity phantom: (a) $12.1 \mathrm{kPa}$; (b) $3.5 \mathrm{kPa}$.

\section{B. Rheological model}

There is a physical link between the propagation of shear waves in a viscoelastic medium and their viscoelastic properties. ${ }^{26,27}$ In particular, the frequency behaviour of tissue mechanical parameters may be modelled as a power

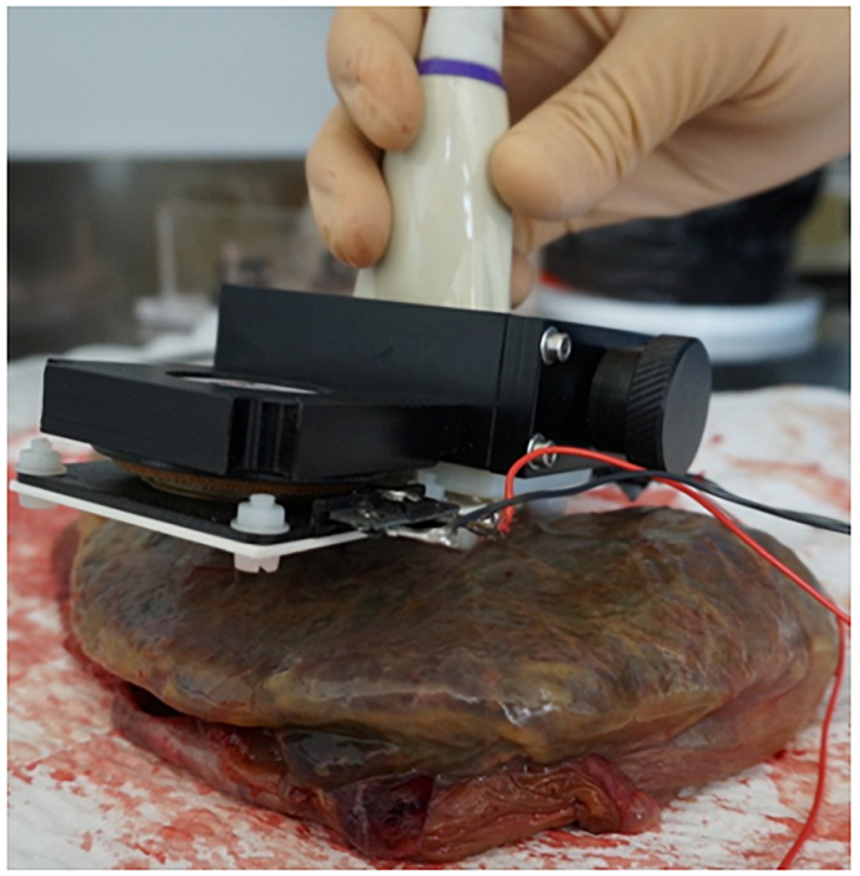

FIG. 11. Ex vivo measurement in placenta.

law, in which case the exponent parameter represents a mechanical property inherent to a given material. ${ }^{28-30}$ This behaviour can also not be modelled by the classical Voigt model widely used in elastography. The Voigt model predicts a constant dynamic modulus $G^{\prime}(\omega)$ as a function of frequency and a linearly rising loss modulus $G^{\prime \prime}(\omega)=\omega^{1}$, which is in obvious contradiction with a fractional law behaviour. A rheological model that is capable of describing power law behaviour for the complex shear modulus is the so-called springpot model. This model has its mechanical interpretation in terms of a hierarchical organization of springs and dashpots ${ }^{29}$ and can continuously interpolate between a pure solid material (exponent parameter $\gamma=0$ ) and a pure liquid $(\gamma=1)$ material with respect to the power law exponent for $G^{*}(\omega)=G^{\prime}(\omega)+i G^{\prime \prime}(\omega) \sim \omega^{y}$.

As presented in Fig. 13, two different models have been used to fit the experimental data obtained with the TE method: the classical Voigt model and a fractional rheological model developed by Nicole et al. ${ }^{31}$

$$
G^{*}(i \omega)=G_{e}+K \cdot[i \omega]^{n} .
$$
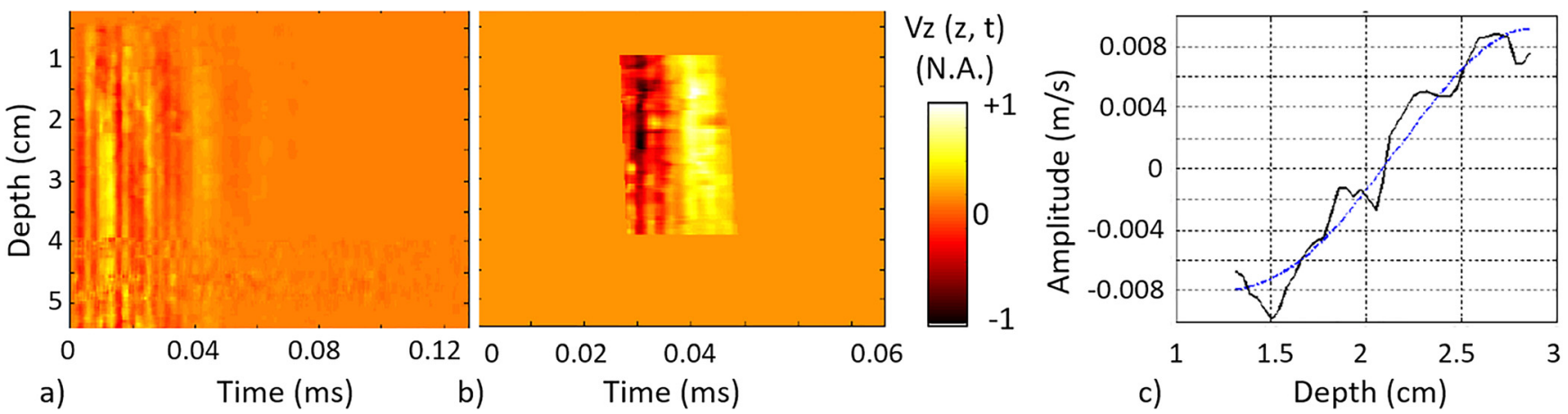

FIG. 12. Example of an ex vivo measurement in the placenta: (a) Particle velocity Vz(z,t) (normalized amplitude); (b) Segmentation of (a) to keep only the incident shear wave; (c) Interpretation of the real part of $\mathrm{Vz}(\mathrm{z}, \omega)$ using plane wave approximation. 


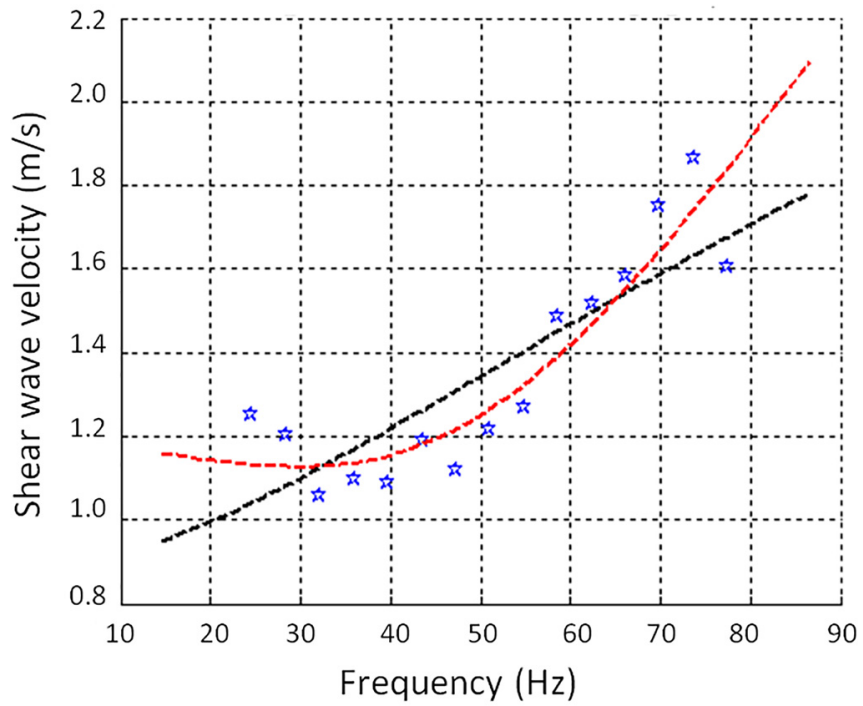

FIG. 13. Shear wave velocity dispersion in a placenta (ex vivo measurement). Stars: experimental data; black line: fit with the Voigt model; red line: fit with the fractional model.

In this last model, the frequency behavior is modeled as a power law. The exponent parameter $\mathrm{n}$ represents a mechanical property inherent to a given material. Measurements have been performed in the bandwidth $[20 \mathrm{~Hz}-80 \mathrm{~Hz}]$.

This parameter $\mathrm{n}$ depends in particular, on the shape of the tissue under consideration, and this tissue shape is modified in the case of placental insufficiency. In addition, the villous tree is a structure measuring several centimeters and occupying the entire thickness of the placenta. Before studying abnormal placentas, we wished to obtain data from normal placentas.

\section{Results and discussion}

Table I presents results of shear wave velocity measured with both SSI and TE (at $50 \mathrm{~Hz}$ ), and values of parameter $n$ obtained from the dispersion curves (fit with the fractional model). In agreement with the literature, elasticity measured at a fixed frequency by SWE and TE is in the same order of magnitude for both regions. That is why the results presented in Table I are taken into account for all the measurements in both regions. We do not know the frequency bandwidth of the Young's modulus measurement by SWE, which is highly dependent on the observed organ. It is therefore difficult to compare precisely our results with the values given by SWE. The group velocity measured by SWE and that estimated by $\mathrm{TE}$ at $50 \mathrm{~Hz}$ are, however, relatively close.

Moreover, we observe that values of celerities and parameter $\mathrm{n}$ are in the same order as values obtained with the previously developed plane shear wave TE method. ${ }^{17}$ However, standard deviations found in the present study are higher than those with the previous method, not adapted for in vivo measurements. First, in the present 2D TE method, the shear wave is not a plane wave, as presented in Figs. 5 and 6, inducing a bias in the measurement. Second, the system is no more fixed but maintained in the hand. The position of the US probe is then never exactly the same, and the
TABLE I. Ex vivo measurements in 20 placentas.

\begin{tabular}{lccccc}
\hline \hline Placenta & Cs SSI (m/s) & Cs TE $(\mathrm{m} / \mathrm{s})$ & STD $(\mathrm{m} / \mathrm{s})$ & $\mathrm{n}$ & STD \\
\hline 1 & 1.53 & 1.89 & 0.39 & 1.31 & 0.27 \\
2 & 1.42 & 1.42 & 0.4 & 1.41 & 0.18 \\
3 & 1.66 & 1.61 & 0.64 & 1.29 & 0.25 \\
4 & 1.54 & 1.11 & 0.29 & 1.40 & 0.12 \\
5 & 1.58 & 1.58 & 0.33 & 1.32 & 0.09 \\
6 & 1.66 & 1.38 & 0.45 & 1.35 & 0.15 \\
7 & 1.54 & 1.45 & 0.58 & 1.21 & 0.18 \\
8 & 1.40 & 1.26 & 0.22 & 1,28 & 0.11 \\
9 & 1.81 & 1.26 & 0.22 & 1.35 & 0.19 \\
10 & 1.83 & 1.91 & 0.44 & 1.28 & 0.09 \\
11 & 1.88 & 2.81 & 1.07 & 1.10 & 0.20 \\
12 & 1.54 & 1.73 & 0.46 & 1.23 & 0.17 \\
13 & 1.57 & 2.6 & 0.36 & 1.32 & 0.1 \\
14 & 2.1 & 2.6 & 0.43 & 1.22 & 0.18 \\
15 & 1.93 & 1.7 & 0.53 & 1.42 & 0.08 \\
16 & 2.22 & 1.9 & 0.6 & 1.2 & 0.2 \\
17 & 2.07 & 1.78 & 0.33 & 1.16 & 0.16 \\
18 & 1.6 & 1.54 & 0.76 & 1.42 & 0.17 \\
19 & 2.83 & 2.63 & 0.57 & 1.07 & 0.18 \\
20 & 1.81 & 1.56 & 0.29 & 1.05 & 0.25 \\
\hline \hline
\end{tabular}

pre-stress applied to the placenta different at each measurement, inducing a lower reproducibility.

However, the velocity values found in our study had the same order of magnitude as those found in other studies, either ex vivo ${ }^{6}$ (mean Cs: $1.31 \mathrm{~m} / \mathrm{s}$ ) or in vivo ${ }^{7}$ (median $\mathrm{E}$ : $4 \mathrm{kPa}$ ). A low inter-individual variation of the different parameters is found. Perspectives of this work will be to test the sensitivity of this 2D TE system to distinguish these biomechanical parameters between IUGR and healthy placentas. This will help to conclude about the added-value of the elasticity frequency analysis for placental exploration.

The correlation coefficient $r$ has been calculated for the two models. We found $r=0.926 \pm 0.031$ for the Voigt model, and $r=0.94 \pm 0.026$ for the fractional model. The correlation coefficient of the fractional model is therefore slightly higher. This result is consistent with the fact that the fractional model takes into account the power law of the dispersion, unlike the Voigt model.

As previously stated, the nonlinear fit is made both on the real and imaginary parts of $\mathrm{Vz}(\mathrm{z}, \omega)$. This gives a certain robustness to the method because a slowly varying curve such as a maximum of sinusoid, where the fit is difficult to achieve, is counterbalanced by a rapidly varying curve such as the passage of a sine to 0 (real and imaginary parts in phase quadrature), where the fit is more efficient. From experience, half a wavelength is needed to correctly fit in vivo data. In the case of a $4 \mathrm{~cm}$ placenta, therefore the wavelength is $8 \mathrm{~cm}$ and the minimum frequency is $37 \mathrm{~Hz}$ for a shear wave velocity of $3 \mathrm{~m} / \mathrm{s}$ (unfavorable case of preeclampsia).

For in vivo application, the shear wave must cross several types of different tissues (skin, fat, muscle, etc.) before reaching the placenta. Even if the presence of fat, for example, does not seem to modify the dispersion curve of the shear wave, ${ }^{32}$ all these tissues will lengthen the propagation distance of the wave which is in this case more attenuated by 
diffraction and viscosity. The presence of multiple interfaces can induce compression waves from shear waves by mode conversion, and inversely. If the latter effect is not negligible in the study of the placenta, the directivity pattern of the shear wave in the organ can be strongly modified and may limit the relevance of our method. In this case, we will have to use more suitable methods such as passive elastography ${ }^{33}$ which does not need a precise directivity of the shear wave.

\section{CONCLUSION AND PERSPECTIVES}

Many studies found in the literature suggest that consistency of placentas with vascular pathology may differ from the consistency of normal placentas. The objective of the study was to develop an optimized 2D TE system adapted to in vivo placenta exploration. Feasibility of the method for placental exploration has been demonstrated, and reproducibility of celerity and parameter $\mathrm{n}$ values has been studied.

Future work will consist of ex vivo and in vivo measurements comparing normal and IUGR placentas. A clinical protocol on 2 groups (normal and IUGR) during the third trimester of pregnancy is then planned.

${ }^{1}$ K. S. Khan, D. Wojdyla, L. Say, A. M. Gulmezoglu, and P. F. A. Van Look, "WHO analysis of causes of maternal death: A systematic review," Lancet 367, 1066-1074 (2006).

${ }^{2}$ X. Zhang, K. S. Joseph, and M. S. Kramer, "Decreased term and postterm birthweight in the United States: Impact of labor induction," Am. J. Obstet. Gynecol. 203(2), 124.e1-7 (2010).

${ }^{3}$ G. C. Smith, M. F. Smith, M. B. McNay, and J. E. Fleming, "The relation between fetal abdominal circumference and birthweight: Findings in 3512 pregnancies," Br. J. Obstet. Gynaecol. 104(2), 186-190 (1997).

${ }^{4}$ L. Bricker, N. Medley, and J. J. Pratt, "Routine ultrasound in late pregnancy (after 24 weeks' gestation)," Cochrane Database Syst. Rev. 6, CD001451 (2015).

${ }^{5}$ S. P. Chauhan, D. J. Rouse, C. V. Ananth, E. F. Magann, E. Chang, J. D. Dahlke et al., "Screening for intrauterine growth restriction in uncomplicated pregnancies: Time for action," Am. J. Perinatol. 30(1), 33-39 (2013).

${ }^{6}$ M. Sugitani, Y. Fujita, K. Fukushima, T. Takeuchi, and M. Shimokawa, "A new method for measurement of placental elasticity: Acoustic radiation force impulse imaging," Placenta 34, 1009-1013 (2013).

${ }^{7}$ F. Kilic, Y. Kayadibi, M. A. Yuksel, I. Adaletli, F. E. Ustabasioglu, M. Oncul et al., "Shear wave elastography of placenta: In vivo quantitation of placental elasticity in preeclampsia," Diagn. Interventional Radiol. 21(3), 202-207 (2015).

${ }^{8} \mathrm{~S}$. Holm and R. Sinkus, "A unifying fractional wave equation for compressional and shear waves," J. Acoust. Soc. Am. 127, 542-548 (2010).

${ }^{9}$ L. Macara, J. C. Kingdom, P. Kaufmann et al., "Structural analysis of placental terminal villi from growth-restricted pregnancies with abnormal umbilical artery Doppler waveforms," Placenta 17, 37-48 (1996).

${ }^{10}$ P. Kaufmann, T. M. Mayhew, and D. S. Charnock-Jones, “Aspects of human fetoplacental vasculogenesis and angiogenesis. II. Changes during normal pregnancy," Placenta 25(2-3), 114-126 (2004).

${ }^{11}$ T. M. Mayhew, D. S. Charnock-Jones, and P. Kaufmann, "Aspects of human fetoplacental vasculogenesis and angiogenesis. III. Changes in complicated pregnancies," Placenta 25(2-3), 127-139 (2004).

${ }^{12}$ C. M. Scifres and D. M. Nelson, "Intrauterine growth restriction, human placental development and trophoblast cell death," J. Physiol. 587, 3453-3458 (2009).
${ }^{13}$ J. M. Abeysekera, M. Ma, M. Pesteie, J. Terry, D. Pugash, J. A. Hutcheon, C. Mayer, L. Lampe, S. Salcudean, and R. Rohling, "SWAVE Imaging of Placental Elasticity and Viscosity: Proof of Concept," Ultrasound Med. Biol. 43(6), 1112-1124 (2017).

${ }^{14}$ E. G. Simon and S. Callé, "Safety of elastography applied to the placenta: Be careful with ultrasound radiation force," J. Obstet. Gynaecol. Res. 43(9), 1509 (2017).

${ }^{15} \mathrm{~S}$. Catheline, F. Wu, and M. Fink, "A solution to diffraction biases in sonoelasticity: The acoustic impulse technique," J. Acoust. Soc. Am. 105(5), 2941-2950 (1999).

${ }^{16}$ E. Nicolas, S. Callé, S. Nicolle, D. Mitton, and J. P. Remenieras, "Biomechanical characterization of ex vivo human brain using ultrasound shear wave spectroscopy," Ultrasonics 84, 119-125 (2018).

${ }^{17}$ E. G. Simon, S. Callé, F. Perrotin, and J. P. Remenieras, "Measurement of shear wave speed dispersion in placenta using transient elastography: A preliminary ex vivo study," PloS ONE 13(4), e0194309 (2018).

${ }^{18}$ L. Sandrin, M. Tanter, S. Catheline, and M. Fink, "Shear modulus imaging with 2-D transient elastography," IEEE UFFC 49(4), 426-435 (2002).

${ }^{19} \mathrm{~K}$. Aki and P. G. Richards, Quantitative Seismology-Theory and Methods (W. H. Freeman and Company, 1980).

${ }^{20}$ S. Callé, J. P. Remenieras, O. Bou Matar, and F. Patat, "Temporal analysis of tissue displacement induced by a transient ultrasound radiation force," J. Acoust. Soc. Am. 118(5), 2829-2840 (2005).

${ }^{21}$ S. Callé, J. P. Remenieras, M. Elkateb, and F. Patat, "Shear wave elastography: Modeling of the shear wave propagation in heterogeneous tissue by pseudospectral method," in Proceedings of IEEE Ultrasonics Symposium, Rotterdam, Netherlands (2005), pp. 24-27.

${ }^{22}$ L. Sandrin, D. Cassereau, and M. Fink, "The role of the coupling term in transient elastography," J. Acoust. Soc. Am. 115(1), 73-83 (2004).

${ }^{23} \mathrm{~N}$. Benech and C. Negreira, "Longitudinal and lateral low-frequency head wave analysis in soft media," J. Acoust. Soc. Am. 117(6), 3424-3431 (2005).

${ }^{24}$ A. Hoeks, P. Brands, T. Arts, and R. Reneman, "Subsample volume processing of Doppler ultrasound signals," Ultrasound Med. Biol. 20(9), 953-965 (1994).

${ }^{25}$ J. Oudry, C. Bastard, V. Miette, R. Wiilinger, and L. Sandrin, "Copolymer-in-oil phantom materials for elastography," Ultrasound Med. Biol. 35(7), 1185-1197 (2009).

${ }^{26}$ T. L. Szabo and J. Wu, "A model for longitudinal and shear wave propagation in viscoelastic media," J. Acoust. Soc. Am. 107(5), 2437-2446 (2000).

${ }^{27}$ S. Catheline, J. L. Genisson, G. Delon, M. Fink, R. Sinkus, S. Abouelkaram, and J. Culioli, "Measurement of viscoelastic properties of homogeneous soft solid using transient elastography: An inverse problem approach," J. Acoust. Soc. Am. 116(6), 3734-3741 (2004).

${ }^{28}$ R. Bagley and P. Torvik, "A theoretical basis for the application of fractional calculus to viscoelasticity," J. Rheol. 27(3), 201-210 (1983).

${ }^{29}$ H. Schiessel, R. Metzler, A. Blumen, and T. F. Nonnenmacher, "Generalized viscoelastic models: Their fractional equations with solutions," J. Phys. A: Math. Gen. 28, 6567-6584 (1995).

${ }^{30}$ B. Robert, R. Sinkus, B. Larrat, M. Tanter, and M. Fink, "A New Rheological Model Based on Fractional Derivatives for Biological Tissues," in Proceedings of IEEE Ultrasonics Symposium, Vancouver, Canada (2006), pp. 1033-1036.

${ }^{31}$ S. Nicolle, P. Vezin, and J. F. Palierne, "A strain-hardening bi-power law for the nonlinear behaviour of biological soft tissues," J. Biomech. 43, 927-932 (2010).

${ }^{32}$ K. R. Nightingale, N. C. Rouze, S. J. Rosenzweig, M. H. Wang, M. F. Abdelmalek, C. D. Guy, and M. L. Palmeri, "Derivation and analysis of viscoelastic properties in human liver: Impact of frequency on fibrosis and steatosis staging," IEEE UFFC 62(1), 165-175 (2015).

${ }^{33}$ T. Gallot, S. Catheline, P. Roux, K. Brum, N. Benech, and C. Negreira, "Passive elastography: Shear-wave tomography from physiological-noise correlation in soft tissues," IEEE UFFC 58(6), 1122-1126 (2011). 